\title{
Using ePortfolio-based learning approach to facilitate knowledge sharing and creation among college students
}

\author{
Chi-Cheng Chang \\ National Taiwan Normal University \\ Pao-Nan Chou \\ National University of Tainan \\ Chaoyan Liang \\ National Taiwan University
}

\begin{abstract}
The purpose of the present study was to examine the effects of the ePortfolio-based learning approach (ePBLA) on knowledge sharing and creation with 92 college students majoring in electrical engineering as the participants. Multivariate analysis of covariance (MANCOVA) with a covariance of pretest on knowledge sharing and creation was conducted for examining differences in knowledge sharing and creation between an experimental group (a total of 47 participants using ePBLA) and a control group (a total of 45 participants not using ePBLA or creating eportfolio). A $t$-test was also performed for examining the differences in knowledge sharing and creation of the experimental group before and after using ePBLA. The results showed that: a) the experimental group had significantly better knowledge sharing and creation than the control group; and b) the experimental group had significantly better knowledge sharing and creation after using ePBLA. The results implied that ePBLA facilitated knowledge sharing and creation. Furthermore, relationships between knowledge sharing and creation were also enhanced by the use of ePBLA.
\end{abstract}

\section{Introduction}

\section{ePortfolio-based learning}

Electronic portfolio (ePortfolio) based learning (ePBL) is a learning approach for learners to achieve selfdevelopment and progress by using eportfolios to systematically collect evidence about their learning progresses and efforts, as well as to review their learning progress and present their learning performance according to their leaning goals and reflections. Under ePBLA, instructors act as guides to integrate ePortfolios into teaching and learning. Responsibilities for an instructor using ePBLA include teaching students how to create an ePortfolio, set learning goals, write reflections, perform self-assessment, and provide peer feedback (Danielson \& Abrutyn, 1997; Higher Education Funding Council for England [HEFCE], 2008). ePortfolios are helpful to learning when they act not only as a discrete entity, but also as a learning or teaching strategy (Hartnell-Young et al., 2007). An ePortfolio cannot only be a storage for evidence, it should be applied to teaching and learning in order to make it effective (HEFCE, 2008). Therefore, ePortfolios must be integrated into learning or teaching for a learning or teaching strategy in order to be effective. This shows the importance of ePortfolios as a learning or teaching strategy.

ePortfolios save and display data through digitalisation. The Internet allows peers to share their ePortfolios with one another without limitations of spaces and artefact types. Learners can set learning goals and reflect, as well as systematically accumulate, collect, and present their artefacts. A study done by Chau and Cheng (2010) suggested that ePortfolios support independent learning through processes of planning, monitoring, and reflection. These processes are positively support learners' learning processes and performance, and provide self-development opportunities (Cavaller, 2011; McMullan, 2006). Since learners can show individual abilities through ePortfolios, they can be used to save learners' learning progresses. The development processes of an ePortfolio include learning-goal setting, data collection, reflection, artefact modification, artefact collection, artefact presentation, learning content arrangement, self-assessment, peer assessment, peer observing and emulating, and peer feedback (Coombe \& Barlow, 2004; Hughes, 2008; Joyes, Gray, \& Hartnell-Young, 2010; Sharma, 2007). Among these processes, artefact presentation, peer assessment, peer observing and emulating, and peer feedback via the Internet relate to knowledge sharing, whereas reflections, artefact modification, and learning content arrangement via the Internet are relevant to knowledge creation (Chang, Liang, Tseng, Tseng, \& Chen, 2013; Chang, Tseng, Liang, \& Chen, 2013). 
Chau and Cheng (2010) argued that during the development of ePortfolios, learners are able to achieve knowledge construction through sharing with peers and instructors. Although knowledge construction and knowledge creation differ from each other, their conceptions are similar. With the support of digital technology, ePortfolios are more convenient than paper-based portfolios because they are positive to knowledge sharing and facilitate knowledge creation. These statements are only explanations of concepts because they need to be further confirmed by empirical studies (Chang, Liang et al., 2013; Chang, Tseng et al., 2013). Whether or not ePortfolios facilitate knowledge sharing and creation is a worthy issue to be examined.

\section{Process of ePortfolio-based learning approach}

Many studies have discussed various ePortfolio-based learning approaches (ePBLAs). The six steps to ePBLA proposed by HEFCE (2008) included: (1) to define (to set goals for ePortfolio, to confirm types of ePortfolio and creating tools, as well as to make sure learners' needs and features of learning environment); (2) to understand (to understand learning outcomes that a student should achieve); (3) to prepare (to train instructors and students, as well as to allow instructors and students to understand ePortfolios); (4) to engage (to determine the most effective strategies for engaging and sustaining the commitment of learners as well as supporting learners' use of ePortfolios); (5) to implement (to carry out eportfolios); and (6) to review (to assess students' learning outcomes). Although the range covered by the process of ePBLA proposed by HEFCE was broad, it could support student learning (e.g. review/assessment).

A guide to the stages in portfolio development and reviews/assessment done by Challis (1999) included: a) to develop a framework and documentation for portfolio; b) to establish means for supporting learners during portfolio development; c) to introduce portfolio to learners; d) to develop individual action plan; e) to identify sources of evidence of learning appropriate to identified learning needs; f) to gather and document evidence of learning; g) to monitor process, h) to assess/review portfolios, and i) to report results to appropriate bodies. However, the range covered by the process of ePBLA proposed by Challis was too broad, but could support student learning (e.g., review/assessment).

An ePortfolio assessment approach established by Chang and Tseng (2009) involved: preparation (to introduce ePortfolios and to explain how to create ePortfolios); implementation (to set learning goals, to present artefacts, to write reflections, to observe artefacts, to self-assess, and to give peer feedback); and presentation (to present ePortfolios and to explain thoughts toward creation). Compared to Challis (1999), the range covered by the approach established by Chang and Tseng was a little bit narrow, but it was more specific, clear, and focused. It also tended to describe the approach from the learners' perspective. Chang and Tseng's (2009) approach emphasised web ePortfolio-based assessment activities, which supported student learning (e.g., reflection, presentation, and assessment).

A process for developing a portfolio stated by Danielson and Abrutyn (1997) contained collection, selection, reflection, projection, and presentation. Collection means what materials and artefacts will be collected depending on portfolio purposes. Selection indicates the selection criteria for materials to be included in a portfolio. Reflection includes reflections on learners' learning processes and outcomes depending on every entry in a portfolio. Projection means reviewing learners' reflections on learning, making evaluation and deciding future directions. Presentation means sharing the portfolio with peers and receiving feedback. The approach stated by Danielson and Abrutyn focused on the development of paperbased portfolios, which could support student learning (e.g., reflection, presentation, and evaluation). Their approach could also be applied to ePortfolios.

An ePortfolio development process proposed by Barrett (2000a, 2000b) integrated a multimedia development process with the portfolio development process, and included five stages. Barrett's stages of the ePortfolio development process consisted of: (a) defining the portfolio context and goals (multimedia development - decide/assess; portfolio development - purpose and audience); (b) working portfolio (multimedia development - design/plan; portfolio development - collect); (c) reflective portfolio (multimedia development - develop; portfolio development - select, reflect, and direct); (d) connected portfolio (multimedia development - implement; portfolio development - inspect, perfect, and connect); and (e) presentation portfolio (multimedia development - present, publish, and evaluate; portfolio development - respect and celebrate). The approach proposed by Barrett focused on the development and 
use of multimedia ePortfolios, which could support student learning (e.g., reflection, presentation, and evaluation).

In sum, since each approach holds its own background and context, key points stressed by each approach were not exactly the same. However, each approach mentioned review, and evaluation or assessment at least, which implied that assessment and ePortfolio were closely related to each other. Although ePBLA does not require ePortfolio-based assessments, assessments can make ePBLA more complete. The comparisons among different ePBLA approaches are summarised as Table 1.

Table 1

The comparisons among different ePBLA approaches

\begin{tabular}{|c|c|c|c|}
\hline Source & Title & Portfolio type & Learning support \\
\hline $\begin{array}{l}\text { HEFCE } \\
(2008)\end{array}$ & $\begin{array}{l}\text { Process of six steps } \\
\text { (define, understand, prepare, } \\
\text { engage, implement, review) }\end{array}$ & Paper-based portfolio & Review/assessment \\
\hline $\begin{array}{l}\text { Challis } \\
\text { (1999) }\end{array}$ & $\begin{array}{l}\text { Guide to the stages in portfolio } \\
\text { development and } \\
\text { reviews/assessment }\end{array}$ & Paper-based portfolio & Review/assessment \\
\hline $\begin{array}{l}\text { Chang and } \\
\text { Tseng } \\
\text { (2009) }\end{array}$ & $\begin{array}{l}\text { ePortfolio assessment approach } \\
\text { (preparation, implementation, } \\
\text { presentation) }\end{array}$ & Web-based portfolio & $\begin{array}{l}\text { Reflection, presentation, } \\
\text { and assessment }\end{array}$ \\
\hline $\begin{array}{l}\text { Danielson } \\
\text { and } \\
\text { Abrutyn } \\
\text { (1997) }\end{array}$ & $\begin{array}{l}\text { Process for developing a portfolio } \\
\text { (collection, selection, reflection, } \\
\text { projection, and presentation) }\end{array}$ & Paper-based portfolio & $\begin{array}{l}\text { Reflection, presentation, } \\
\text { and evaluation }\end{array}$ \\
\hline $\begin{array}{l}\text { Barrett } \\
(2000 a, \\
2000 b)\end{array}$ & $\begin{array}{l}\text { ePortfolio development process } \\
\text { (defining, working, reflection, } \\
\text { connection, presentation) }\end{array}$ & $\begin{array}{l}\text { Multimedia } \\
\text { ePortfolio }\end{array}$ & $\begin{array}{l}\text { Reflection, presentation, } \\
\text { and evaluation }\end{array}$ \\
\hline
\end{tabular}

\section{ePortfolio and knowledge sharing and creation}

Knowledge sharing refers to the behaviour where learners or workers mutually provide valuable information or ideas among peers. Knowledge creation refers to the behaviour where learners or workers produce new or original ideas which are useful to their learning or jobs. Effects of ePortfolios on knowledge sharing and creation can be explored from activities in its development process. Robinson (2006) argued that learning-goal setting can facilitate learners' self-reflection and self-feedback, whereas reflection and feedback allow learners to enjoy sharing. Moreover, reflection can facilitate learners' thinking and innovation (Metz \& Albernhe-Giordan, 2010). Therefore, learning-goal setting and reflection in ePortfolios are beneficial to knowledge sharing and knowledge creation. During the development process of ePortfolios, students would create new ideas through reflections (Coombe \& Barlow, 2004; Metz \& Albernhe-Giordan, 2010), in order to improve their works (Akcil \& Arap, 2009; Chau \& Cheng, 2010; Gülbahar \& Tinmaz, 2006). Since relationships between new ideas and artefact improvement with knowledge creation exist, reflections with the use of ePortfolios are helpful to knowledge creation.

Artefact sharing among peers can facilitate learners' improvement on artefacts (Buyukduman \& Sirin, 2010). Artefact sharing and improvement are common behaviours performed by learners during the development process of ePortfolios. During artefact sharing and improvement, new ideas are produced, demonstrating that artefact improvement is helpful for knowledge creation. Self-assessment and peer assessment in ePortfolios not only require knowledge application, but also stimulate students to create new ideas (Lee, Goh, Chua, \& Luyt, 2009). Knowledge sharing, can be facilitated through peer assessment, and also by observing and emulating (Wray, 2007). Therefore, self-assessment, peer assessment, and observing and emulating in portfolios are helpful for knowledge sharing creation. Feedback in ePortfolios makes learners willing to share knowledge actively (Cavaller, 2011), which may innovate knowledge (Chang, Liang et al., 2013; Chang, Tseng et al., 2013). Therefore, peer feedback in ePortfolios may facilitate knowledge sharing and creation. The above-mentioned behaviours, including learners' self-assessment, peer assessment, peer observing and emulating, and peer feedback, are common learning activities. Overall, ePortfolios can be a tool for knowledge sharing and creation. In other words, ePBL can enhance knowledge sharing and creation. 


\section{Gap between the present study and previous studies}

The study results from Metz and Albernhe-Giordan (2010) showed that the use of ePortfolios enhanced learners' creativity. This was also confirmed by Hartnell-Young et al. (2007). Although the meanings of creativity and knowledge creation are similar, whether the use of ePortfolios can also facilitate knowledge creation still needs to be further examined. A study done by Peet et al. (2011) confirmed that ePortfolios facilitated knowledge presentation and integration based on the perspective of integrative learning, but the study was not about knowledge sharing and creation. Bozhko and Heinrich (2011) proposed a concept map about a framework for knowledge management of ePortfolios, but did not focus on knowledge sharing and creation. The tool for knowledge management was only a concept map, not an ePortfolio, and was described only based on a theory because it was not confirmed by an empirical study.

In the development of ePortfolios, learners can share learning outcomes with one another through peer assessment, peer observing and emulating, as well peer feedback, which is similar to knowledge sharing. ePortfolios allow learners to organise and present learning outcomes (Lorenzo \& Ittelson, 2005). The presentation of learning outcomes belongs to knowledge sharing behaviour, whereas the organisation of learning outcomes is a source of knowledge creation. Reflections on artefacts can stimulate new ideas (Coombe \& Barlow, 2004; Metz \& Albernhe-Giordan, 2010) which might enhance knowledge creation. In short, activities in the development process of ePortfolios can probably facilitate knowledge sharing and creation. However, most of the above-mentioned studies were about descriptions of theories, not supported by empirical studies, and not about ePortfolios. Research about effects of ePortfolios on knowledge sharing and creation is almost none, therefore it is necessary to conduct an empirical study to confirm the effects.

\section{Research purposes and questions}

The above-mentioned background justifies the present study, the purpose of which was to examine the effects of ePBLA on students' knowledge sharing and creation. The research questions are:

1. For the experimental group, are there any significant differences in knowledge sharing and creation before and after using ePBLA?

2. Are knowledge sharing and creation significantly better than before using ePBLA?

3. Are there any significant differences in knowledge sharing and creation between the experimental group using ePBLA and the control group without using ePBLA?

4. Does the experimental group perform significantly better than the control group?

\section{Research method}

\section{Participants}

The participants were 92 third-year undergraduates, with 65 males and 27 females, from two classes of programming language at a university. The participants were randomly assigned to either the experimental group or the control group. There were a total of 47 students, with 33 males and 14 females, in the experimental group using ePBLA. The software, FrontPage, was used as a tool for creating an ePortfolio and saving learning processes and outcomes. In the control group there were a total of 45 students, with 32 males and 13 females, not using ePBLA or creating ePortfolios. Two 1-hour class periods were held each week. The experiment took 9 weeks. Class environment, course contents, class hours, and class schedules were the same for both groups. The instructor was also the same for both groups in order to avoid any differences in teaching.

Students majoring in electrical engineering were proficient in computer operations, familiar with FrontPage, and good at creating ePortfolios. The curriculum of programming language provided many opportunities to practice and discuss, which was appropriate as a record for reflections. The students were required to complete two artefacts: (a) a comparison and analysis of programming language; and b) a case analysis for computer programming. The artefacts required analyses and reorganisation, which was appropriate for reflections. Reflections and artefact presentations were the main in class ePortfolio activities. 


\section{Research design and framework}

Pretest-posttest control-group design of quasi-experimental research design was applied. A pretest on knowledge sharing and creation was conducted for both groups as a covariance of statistical analyses. A posttest on knowledge sharing and creation was administered to both groups after the treatment of the experiment.

Methods for data analyses included: (a) dependent-sample $t$-test examining differences in knowledge sharing and creation before and after the use of ePBLA for the experimental group; (b) multivariate analysis of covariance (MANCOVA) with the covariance of pretest on knowledge sharing and creation for examining differences in knowledge sharing and creation between both groups; and (c) Pearson's correlation approach for examining relationships between knowledge sharing and creation.

\section{Experiment}

The ePBLA applied was based on the ePortfolio development process (Barrett, 2000a, 2000b), the guide to the stages in portfolio development and reviews/assessment (Challis, 1999), the ePortfolio assessment approach (Chang \& Tseng, 2009), the process for developing a portfolio (Danielson \& Abrutyn, 1997), and the six steps to ePBLA (HEFCE, 2008). The ePBLA was as specific as possible and focused on learning activities in the development and use of ePortfolios. The students in the experimental group used ePBLA to record their learning progresses and outcomes in ePortfolios. Learning activities included learning-goal setting, reflection, artefact presentation, artefact observing and emulating, artefact improvement, student self-assessment, and peer feedback. The instructor played a role of guidance for integrating ePortfolios into instructions. The responsibilities for the instructor were guiding students how to: (a) create ePortfolios, (b) set learning goals, (c) write reflections, (d) self-assess; and (e) provide peer assessment and feedback. The control group did not use ePBLA or ePortfolios.

There were three phases for the experiment, including preparation (first week), implementation (from second to eighth week), and presentation (ninth week). Both groups took two 1-hour class periods each week. The course contents consisted of types of programming language, framework of programming language, comparison of programming language, practices on programming, and examples of programming.

The phase for the first week was preparation (pretest on knowledge sharing and creation). The instructor firstly set goals for ePortfolios in the class, and then confirmed the students' needs and features of a learning environment, and ensured they understood learning outcomes to be achieved. Next, for the experimental group, the instructor showed ePortfolios to the students and explained the principles of ePortfolios. The instructor also described how to use FrontPage software to create ePortfolios and provided opportunities for the students to practice. For the control group, the instructor explained the key concepts of course content, paper-based artefact submission, class note arrangement, artefact observing and emulating, and peer feedback. The questionnaire of knowledge sharing and creation was administered to both groups during the classes.

The phase from the second to eighth week was implementation. The instructor started the instruction of the course for both groups. For the experimental group, the students used the FrontPage software to create ePortfolios and uploaded them to an assigned website after the class, so they could share and observe with one another. The students participated in activities for creating the two artefacts, including learning-goal setting, artefact presentation, writing reflections, self-assessment, peer observing and emulating, peer assessment, and peer feedback. Before each week of classes, the students set their own learning goals according to the course content for the week. After each week of classes, the students reviewed whether they achieved their goals and wrote down the reflection. The participants also collected and organised learning content, lecture notes, and lecture photos in their ePortfolios. After each week, the instructor reviewed the students' ePortfolios and reflections, as well as gave feedback. The students also viewed peers' ePortfolios and gave feedback.

After each session (3 weeks) of artefact creation, the instructor reviewed the students' artefacts and provided feedback, and the students participated in activities of self-assessment, discussions, artefact observing and emulating, artefact improvement, peer assessment, and peer feedback. Although the students in the control 
group were not required to create ePortfolios, they still needed to submit paper-based artefacts, make selfassessment, arrange lecture notes, undertake discussions, and view paper-based artefacts. There was no peer assessment and feedback in the control group.

The phase for the ninth week was presentation (posttest on knowledge sharing and creation). The students in the experimental group participated in an oral presentation (including artefact presentation) and explained how they had created their ePortfolios. The students in the experimental group participated in artefact presentation. The students in both groups completed a questionnaire of knowledge sharing and creation after the class. The instructor gave a final assessment toward learning outcomes for both groups.

\section{Questionnaire of knowledge sharing and creation}

Questionnaire development

The questionnaire adopted was revised from the questionnaire of knowledge sharing and creation proposed by Chang and Tsai (2012). The questionnaire was reviewed by the author and the researcher assistant to assure the appropriateness of each item. Input from the reviews of three experts ensured the questionnaire measured the meanings of knowledge sharing and creation, and assured the accuracy of the items. These experts were professionals in the field of ePortfolios and/or knowledge sharing and creation.

The items in the questionnaire explain the activities for developing ePortfolios, including reflection, artefact improvement, artefact self-assessment, rearrangement of learning contents (e.g., notes, handouts, and website resources), peer feedback toward artefact, teacher feedback toward artefact, peer observing and emulating, and discussion. There were a total of 16 items in the questionnaire, with 8 items for knowledge sharing and 8 items for knowledge creation. The questionnaire was a 5-point Likert type. The higher the score, the more a student agreed with the item. Knowledge sharing mainly measured sharing status among peers. The items are listed as follows:

a) I frequently share reflection processes or outcomes with peers.

b) I frequently share artefact improvement processes or outcomes with peers.

c) I frequently share self-assessment processes or outcomes of artefacts with peers.

d) I frequently share notes, handouts, and website resources that I put in order with peers.

e) I frequently share peer feedback toward my artefacts with peers.

f) I frequently share teacher feedback toward my artefacts with peers.

g) I frequently share thoughts of observing and emulating others' artefacts with peers.

h) I frequently spend time on peer sharing and discussions.

Knowledge creation mainly measured students' changes in their thinking and knowledge. The items are listed as follows:

a) I frequently create knowledge with my own thinking style through reflections.

b) I frequently create knowledge with my own thinking style through artefact revisions.

c) I frequently create knowledge with my own thinking style through self-assessments toward artefacts.

d) I frequently create knowledge with my own thinking style through arrangements of learning contents (e.g., notes, handouts, and website resources).

e) I frequently create knowledge with my own thinking style through peer feedback toward my artefact.

f) I frequently create knowledge with my own thinking style through teacher feedback toward my artefact.

g) I frequently create knowledge with my own thinking style through observing and emulating on others' artefacts.

h) I frequently create knowledge with my own thinking style through discussions.

Item analysis

An independent samples $t$-test was conducted to compare the differences in each item between high and low score groups in pretest. The results revealed that $t$ values for all the items were significant, meaning that each item possessed a satisfactory discrimination index. The Pearson's correlation approach was also performed for examining the relationships between the score of each item and the total score of the 
questionnaire. The result revealed that correlation coefficients for all the items were significant, which meant that each item possessed adequate internal consistency.

\section{Validity and reliability}

The Bartlett's test of sphericity was significant. The Kaiser-Meyer-Olkin (KMO) values of sampling adequacy for knowledge sharing and creation questionnaires were all greater than 0.7 (almost 0.8), which is appropriate for factor analysis (Gravetter \& Wallnau, 2008). The proportion of the sample size (92 students) to the total item number (16) of the two questionnaires was greater than 5:1. Therefore, the factor analysis was appropriate to undertake.

A principal components analysis (PCA) with varimax rotation of orthogonal rotation was conducted for the factor analysis, so the information among factors would not overlap and factor loadings were easy to explain (Howell, 2010). Since the factor loading for each item was greater than 0.5, none of the items in the questionnaire had to be deleted (Hair, Black, Babin, \& Anderson, 2010). The two questionnaires with an Eigenvalue greater than 1 were confirmed. The explained variances for the two questionnaires were all greater than $48 \%$ (almost $50 \%$ ), implying that the validity of the questionnaire was adequate.

The reliability coefficients of the knowledge sharing questionnaire for pretest and posttest were greater than 0.8 , as measured by Cronbach's $\alpha$, suggesting that the questionnaire had a relatively high reliability. The knowledge creation questionnaire had the similar result.

\section{Results and discussions}

\section{Differences in knowledge sharing and creation between pretest and posttest}

A dependent-sample $t$-test was performed to examine the differences in the knowledge sharing and creation between pretest and posttest results in both the experimental group and control group simultaneously. For the control group, there were no significant differences $(p>0.05)$ in knowledge sharing and creation before and after the experiment. As shown in Table 2, for the experimental group, there were significant differences $(p<0.01)$ in knowledge sharing and creation before and after the experiment. Students' knowledge sharing and creation after using ePBLA were significantly better than before, which showed that the use of ePBLA had a positive effect on students' knowledge sharing and creation.

The effect size for the dependent-sample $t$-test was $d$. Me was the mean of the pretest for the experimental group. $M c$ was the mean of the posttest for the experimental group. SDc was the standard deviation of the pretest for the experimental group. Therefore, $d=|(M e-M c)|$ /SDc. Determinative standards were: (a) low relationship, . $2>d \geqq .01$; (b); moderate relationship, .5> $\eta^{2} \geqq .2$; (c) moderate-high relationship, .8> $\eta^{2} \geqq .5$; and (d) high relationship, $\eta^{2} \geqq .8$ (Cohen, 1988). As shown in Table 2 , the effect sizes, ePBLA had a moderate-high relationship with knowledge sharing and creation. The effect size of knowledge sharing was greater than knowledge creation, showing that ePBLA facilitated knowledge sharing more than knowledge creation.

Table 2

The t-test for the differences in knowledge sharing and creation of the experimental group between pretest and posttest.

\begin{tabular}{lllllll}
\hline & Pretest & \multicolumn{3}{c}{ Posttest } & \multicolumn{2}{c}{ Effect size } \\
\cline { 2 - 5 } & $M$ & $S D$ & $M$ & $S D$ & & \\
\hline Sharing & 3.71 & .66 & 4.10 & .506 & $3.52^{* *}$ & .61 \\
Creation & 3.63 & .57 & 3.87 & .529 & $2.87 * *$ & .52 \\
\hline
\end{tabular}

${ }^{*} p<.05,{ }^{* *} p<.01$

In addition, a dependent-sample $t$-test was performed to examine the differences in each item of knowledge sharing and creation between pretest and posttest for the experimental group. The results showed that each item was significant $(p<.05)$. For knowledge sharing, the item "I frequently share reflection processes or outcomes with peers", possessed the highest effect size, whereas the item "I frequently share teacher feedback toward my artefacts with peers", possessed the lowest effect size. The result implied that reflection had the greatest effect on knowledge sharing, and teacher feedback had the smallest effect. For knowledge 
creation, the item "I frequently create knowledge with my own thinking style through self-assessments toward artefacts", possessed the highest effect size, whereas the item "I frequently create knowledge with my own thinking style through discussions”, possessed the lowest effect size. The result implied that selfassessment had the greatest effect on knowledge sharing, and discussion had the smallest effect.

\section{Differences in knowledge sharing and creation between the two groups}

An independent sample $t$-test indicated that there were no significant differences in the knowledge sharing and creation pretests between the experimental group and the control group $(p>.05)$. Multivariate analysis of covariance (MANCOVA) was performed to examine the differences in knowledge sharing and creation between the two groups The covariate variable was the pretest of knowledge sharing and creation. As shown in Table 3, Wilk's $\Lambda(p<0.01)$ showed a significant result, indicating that the students in both groups had a significant difference in either knowledge sharing or knowledge creation. The results revealed that both groups were significantly different in knowledge sharing and creation $(p<.001)$. The students in the experimental group were significantly better than the students in the control group in knowledge sharing and creation (Table 4), indicating ePBLA facilitated knowledge sharing and creation.

The determinative standards on effect size for MANCOVA were: (a) low relationship, .059> $\eta^{2} \geqq .01$; (b) moderate relationship, .138> $\eta^{2} \geqq .059$; and (c) high relationship, $\eta^{2} \geqq .138$ (Cohen, 1988). As shown in Table 3, ePBLA had a high relationship with knowledge sharing and creation. The effect size of knowledge sharing was greater than knowledge creation, showing that ePBLA facilitated knowledge sharing more than knowledge creation.

Table 3

MANCOVA summary on posttest of knowledge sharing and creation

\begin{tabular}{lllll}
\hline $\begin{array}{l}\text { Wilk' s } \Lambda \\
(\text { Sig.) }\end{array}$ & Source & Dependent variable & $F$ & Effect size \\
\hline .64 & & & & .12 \\
$\left(.01^{* *}\right)$ & Covariate & Sharing & $10.38^{* *}$ & .10 \\
& & Creation & $8.90^{* *}$ & .36 \\
& Between- & Sharing & $39.68^{* * *}$ & .28 \\
\hline & group & Creation & $28.68^{* * *}$ & \\
\hline
\end{tabular}

${ }^{* *} p<.01,{ }^{* * *} p<.001$; Covariance: pretest on knowledge sharing and creation

Table 4

Adjusted mean for posttest of knowledge sharing and creation

\begin{tabular}{lllll}
\hline & \multicolumn{2}{c}{ Experimental group } & \multicolumn{3}{c}{ Control group } \\
\cline { 2 - 5 } & Adj- $M$ & $S D$ & Adj- $M$ & $S D$ \\
\hline Sharing & 4.17 & .08 & 3.42 & .08 \\
Creation & 3.93 & .07 & 3.35 & .08 \\
\hline
\end{tabular}

An analysis of covariance (ANCOVA) was conducted to examine the differences in each item of knowledge sharing and creation between the experimental group and the control group. From the results it appeared that each item was significant $(p<.05)$. For knowledge sharing, the item "I frequently share self-assessment processes or outcomes with peers", possessed the highest effect size, whereas the item "I frequently share peer feedback toward my artefacts with peers”, possessed the lowest effect size. The result implied that self-assessment had the greatest effect on knowledge sharing, and peer feedback had the smallest effect. For knowledge creation, the item "I frequently create knowledge with my own thinking style through teacher feedback toward my artefact", possessed the highest effect size, whereas the item "I frequently create knowledge with my own thinking style through discussions”, possessed the lowest effect size. The result implied that teacher feedback had the greatest effect on knowledge sharing, and discussion had the smallest effect.

\section{Correlations between knowledge sharing and creation}

As shown in Table 5, for all the students there were significantly positive relationships between knowledge sharing and creation $(p<.05)$. For the experimental group, there were significantly positive relationships between knowledge sharing and creation $(p<.01)$. For the control group, there was no significantly positive 
relationship between knowledge sharing and creation. The result implied that the use of ePBLA increased the strength of the correlations between students' knowledge sharing and creation.

Based on the varieties of correlations from pretest and posttest, for the experimental group, there was no significantly positive relationship between knowledge sharing and creation for the pretest, but there were significantly positive relationships between knowledge sharing and creation for the posttest. The result indicated that the correlations between students' knowledge sharing and creation were enhanced after using ePBLA.

Table 5

Correlations between knowledge sharing and creation

\begin{tabular}{lll}
\hline Students & Pretest & Posttest \\
\hline Experimental group & .12 & $.41^{* *}$ \\
Control group & .14 & .17 \\
Overall & .13 & $.27^{*}$ \\
\hline$* * p<.01,{ }^{* *} p<.001$ & &
\end{tabular}

\section{Discussion}

The students in the experimental group had significantly better knowledge sharing after using ePBLA than before. The experimental group also had significantly better knowledge sharing than the control group. These results confirmed a perspective that the use of ePortfolios can facilitate knowledge sharing as proposed by Lorenzo and Ittelson (2005). Therefore the perspective proposed by Lorenzo and Ittelson, was not proved by empirical study, but was confirmed by the present study. A study done by Wray (2007) revealed that peer assessment as well as observing and emulating facilitated knowledge sharing. A study done by Cavaller (2011) showed that feedback from ePortfolios facilitated learners' active knowledge sharing. These study results were consistent with the results in the present study. For example, students mentioned that knowledge could be shared easily with peers through ePortfolios in their personal ePortfolios:

I have done my best to organize knowledge acquired from classes to notes and save in the ePortfolio each week. After uploading to the Internet, I frequently also explore classmates' ePortfolios to see if they also have organized their notes due to my curiosity. Some classmates have organized very well. After viewing their notes, I have found that there have been some shortcomings in my notes. (Student A)

Classmates have shared their personal ePortfolios on the Internet. We are able to connect to classmate's ePortfolios quickly to view and learn. Based on viewing classmates' artefacts, I have found that there are needs to improve my artefacts. (Student B)

The study results showed that the students in the experimental group had significantly better knowledge creation after using ePBLA than before. The experimental group also had significantly better knowledge creation than the control group. Results found in a study Metz and Albernhe-Giordan (2010) revealed that the use of ePortfolios facilitated learners to create new ideas and enhanced their creativities. This was consistent with the results in the present study. The difference between the study done by Metz and Albernhe-Giordan (2010) and the present study was that the study of Metz and Albernhe-Giordan examined effects of ePortfolios on creativity among university students, and the curriculum adopted in their study was artefact design. A study done by Coombe and Barlow (2004) demonstrated that the process of developing ePortfolios was positive for the students to create new ideas. A study result found by Lee et al. (2009) showed that self-assessment and peer assessment in ePortfolios could stimulate assessors to create new ideas. These outcomes are consistent with the results of the present study. Students mentioned in their personal ePortfolios that reflections, viewing peers' ePortfolios, and arranging notes, could produce new ideas:

I frequently think when writing reflections. I frequently also recall knowledge that I have acquired. Viewing others' ePortfolios has enhanced my reflections and been helpful to my knowledge growth. (Student C) 
I have explored some classmates' ePortfolios this week. Some classmates' artefacts have been done very well which have made me learn a lot from and create some new ideas for improvements. (Student D)

I have read some studies and have written some reflections toward them when I arrange notes this week. Although it has taken me some time, I have felt that I have gained a lot and have had some new findings. By viewing classmate' notes that have been arranged in their eportfolios, I have had some new inspirations toward learning contents this week. (Student E)

\section{Conclusion and implications}

The present study confirmed that ePBLA can facilitate knowledge sharing and creation. Thus, the ePBLA can be integrated with each learning subject because the use of ePortfolio can facilitate learners' knowledge sharing and creation. The majority of previous ePortfolio studies have examined the effects on learning, but almost none of them have examined the effects on knowledge sharing and creation. Therefore, the research results in the present study are meaningful.

The ePBLA facilitated knowledge sharing, indicating that peer observing and emulating as well as peer feedback (i.e., the activities of ePBLA) transferred to knowledge sharing behaviour after a 9-week learning process. The ePBLA facilitated knowledge creation, meaning that reflection, self-assessment, peer observing and emulating, peer assessment, and peer feedback (i.e., the activities of ePBLA) helped students to create new ideas. Overall, the ePBLA can enhance students' knowledge sharing and creation abilities, which can be a tool for knowledge sharing and creation. Therefore, when planning ePBLA, the incidence of activities for knowledge sharing and creation should be increased in order to enhance the effectiveness of ePBLA.

\section{Limitations and future work}

The present study focused on quantitative inference and did not explore qualitative data. This was one of the limitations. For the future, qualitative data, including learning goals set by students, reflective contents, and artefacts can be explored further. This shortcoming as a limitation of the present study might be overcome by using multiple measurement approaches (e.g., achievement test, behaviour observation, and peer-assessment etc.). It could also be interesting to explore all the different and particular ways that knowledge sharing actually promotes learning objectives and/or exactly how it works to give new knowledge to students.

\section{References}

Akcil, U., \& Arap, B. (2009). The opinions of education faculty students on learning processes involving e-portfolios. Procedia Social and Behavioral Sciences, 1(1), 395-400. http://dx.doi.org/10.1016/j.sbspro.2009.01.071

Barrett, H. (2000a). Electronic teaching portfolios: Multimedia skills + portfolio development = powerful professional development. In D. Willis et al. (Eds.), Proceedings of Society for Information Technology \& Teacher Education International Conference 2000 (pp. 1111-1116). Chesapeake, VA: AACE. Retrieved from http://electronicportfolios.com/portfolios/site2000.html

Barrett, H. (2000b). Create your own electronic portfolio. Learning \& Leading with Technology, 27(7), 14-21. Retrieved from http://www.electronicportfolios.com/portfolios/iste2k.html

Bozhko, Y., \& Heinrich, E. (2011). Concept map-based framework for learner-centered knowledge management in ePortfolios. Proceedings of 2011 11th IEEE International Conference on Advanced Learning Technologies (pp.160-162). Athens, GA: IEEE Computer Society. http://dx.doi.org/10.1109/ICALT.2011.53

Buyukduman, I., \& Sirin. S. (2010). Learning portfolio (LP) to enhance constructivism and student autonomy. Procedia Social and Behavioral Sciences, 3, 55-61.

http://dx.doi.org/10.1016/j.sbspro.2010.07.012 
Cavaller, V. (2011). Portfolios for entrepreneurship and self-evaluation of higher education institutions. Procedia Social and Behavioral Sciences, 12(1), 19-23. http://dx.doi.org/10.1016/j.sbspro.2011.02.005

Challis, M. (1999). AMEE medical guide no.11 (revised): Portfolio-based learning and assessment in medical education. Medical Teacher, 21(4), 370-386. Retrieved from http://www.bumc.bu.edu/facdev-medicine/files/2010/06/AMEE-guide-portfolio.pdf

Chang, C.-C., Liang, C., Tseng, K.-H., Tseng, J.-S. \& Chen, T.-Y. (2013). Were knowledge management abilities of university students enhanced after creating personal blog-based portfolios? Australasian Journal of Educational Technology, 29(6), 916-931. http://dx.doi.org/10.14742/ajet.462

Chang, C. C., \& Tsai, C. W. (2012). Developing a knowledge management behavior scale of Web-based portfolio based on approaches of web fuzzy delphi and fuzzy AHP. Journal of Educational Media \& Library Sciences, 50(1), 103-134. http://dx.doi.org/10.6120/JoEMLS.2012.501/0471.RS.CM

Chang, C. C., \& Tseng, K. H. (2009). Use and performances of web-based portfolio assessment. British Journal of Educational Technology, 40(2), 358-370. http://dx.doi.org/10.1111/j.14678535.2008.00885.X

Chang, C.-C., Tseng, K.-H., Liang, C., \& Chen, T.-Y. (2013). Using e-portfolios to facilitate university students' knowledge management performance: e-portfolio vs. non-portfolio. Computers \& Education, 69(6), 216-224. http://dx.doi.org/10.1016/j.compedu.2013.07.017

Chau, J., \& Cheng. G. (2010). Towards the understanding the potential of e-portfolios for independent learning: A qualitative research. Australasian Journal of Educational Technology, 26(7), 932-950. http://dx.doi.org/0.14742/ajet.1026

Cohen, J. (1988). Statistical power analysis for the behavioral sciences (2nd ed.). Hillsdale, NJ: Lawrence Erlbaum Associates. https://www.routledge.com/Statistical-Power-Analysis-for-theBehavioral-Sciences/Cohen/p/book/9780805802832

Coombe, C., \& Barlow, L. (2004). The reflective portfolio: Two case studies from the United Arab Emirates. English Teaching Forum, 41(1), 26-35. Retrieved from https://americanenglish.state.gov/files/ae/resource_files/04-42-1-f.pdf

Danielson, C., \& Abrutyn, L. (1997). An introduction to using portfolios in the classroom. Alexandria, VA: Association for Supervision and Curriculum Development. http://www.ascd.org/publications/books/197171.aspx

Gravetter, F. J., \& Wallnau, L. B. (2008). Statistics for behavioral science (7th ed.). Belmont, CA: Thomson. https://www.amazon.com/Statistics-Behavioral-Sciences-FrederickGravetter/dp/0495095206

Gülbahar, Y., \& Tinmaz, H. (2006). Implement project-based learning and e-portfolio assessment in an undergraduate course. Journal of Research on Technology in Education, 38(3), 309-327. http://dx.doi.org/10.1080/15391523.2006.10782462

Hair, J. F., Black, W. C., Babin, B. J., \& Anderson, R. E. (2010). Multivariate data analysis: A global perspective. New Jersey, NJ: Pearson Education. http://trove.nla.gov.au/work/31617881?q\&versionId=44799236

Hartnell-Young, E., Harrison, C., Crook, C., Joyes, G., Davies, L., Fisher, T., Pemberton, R., \& Smallwood, A. (2007). Impact study of e-portfolio on learning. Coventry, UK: British Educational Communication and Technology Agency. http://dera.ioe.ac.uk/1469/7/becta_2007_eportfolios_report_Redacted.pdf

Higher Education Funding Council for England (2008). Effective practice with e-portfolios: Supporting 21st century learning. England, UK: Higher Education Funding Council for England. http://www.webarchive.org.uk/wayback/archive/20140615090512/http://www.jisc.ac.uk/media/docu ments/publications/effectivepracticeeportfolios.pdf

Howell, D. C. (2010). Statistical methods for psychology (7th ed.). Independence, KY: Cengage Learning. https://www.amazon.com/Statistical-Methods-Psychology-7th-Seventh/dp/B008H5J96Q

Hughes, J. (2008). E-portfolio-based learning: A practitioner perspective. ELiSS, 1(2), 1-12. http://dx.doi.org/10.11120/elss.2008.01020005

Joyes, G., Gray, L., \& Hartnell-Young, E. (2010). Effective practice with e-portfolios: How can the UK experience inform implementation? Australasian Journal of Educational Technology, 26(1), 15-27. http://dx.doi.org/10.14742/ajet.1099

Lee, C. S., Goh, D. H. L., Chua, A. K. K., \& Luyt, B. (2009). Choosing communication portfolios to accomplish tasks: The effects of individual differences. Computers \& Education, 53(4), 1167-1176. http://dx.doi.org/10.1016/j.compedu.2009.05.024 
Lorenzo, G., \& Ittelson, J. (2005). An overview of e-portfolios. Educause Learning Initiative Paper, 1(1), 1-27. Retrieved from https://net.educause.edu/ir/library/pdf/eli3001.pdf

McMullan, M. (2006). Students' perceptions on the use of portfolios in pre-registration nursing education: A questionnaire survey. International Journal of Nursing Studies, 43(3), 333-343. http://dx.doi.org/10.1016/j.ijnurstu.2005.05.005

Metz, S. M. V., \& Albernhe-Giordan, H. (2010). E-portfolio: A pedagogical tool to enhance creativity in student's project design. Procedia Social and Behavioral Sciences, 2(2), 3563-3567. http://dx.doi.org/10.1016/j.sbspro.2010.03.552

Peet, M., Lonn, S., Gurin, P., Boyer, K. P., Matney, M., Marra, T., Taylor, S. H., \& Daley, A. (2011). Fostering integrative knowledge through ePortfolios. International Journal of ePortfolio, 1(1), 11-31. Retrieved from http://www.theijep.com/pdf/ijep39.pdf

Robinson, S. (2006). The mission of the j-blog: Recapturing journalistic authority online. Journalism, 7(1), 65-83. http://dx.doi.org/10.1177/1464884906059428

Sharma, S. (2007). From chaos to clarity: Using the research portfolio to teach and assess information literacy skills. The Journal of Academic Librarianship, 33(1), 127-135. http://dx.doi.org/10.1016/j.acalib.2006.08.014

Wray, S. (2007). Teaching portfolios, community, and pre-service teachers' professional development. Teaching and Teacher Education, 23(7), 1139-1152. http://dx.doi.org/10.1016/j.tate.2006.10.004

\section{Corresponding author: Chi-Cheng Chang, samchang@ntnu.edu.tw}

Australasian Journal of Educational Technology (C) 2018.

Please cite as: Chang, C. C., Chou, P. N., \& Liang, C., (2018). Using ePortfolio-based learning approach to facilitate knowledge sharing and creation among college students. Australasian Journal of Educational Technology, 34(1), 30-41. https://doi.org/10.14742/ajet.2687 